Nebibe Varol, J oan Costa-Font, Alistair McGuire

Do Intemational Launch Strategies of

Pharmaceutical Corporations Respond to

Changes in the Regulatory Environment? 


\section{Do International Launch Strategies of Pharmaceutical Corporations Respond to Changes in the Regulatory Environment?}

Nebibe Varol ${ }^{\mathrm{a}}$, Joan Costa-Font ${ }^{\mathrm{a}, \mathrm{b}}$, Alistair McGuire ${ }^{\mathrm{a}}$

${ }^{\text {a }}$ LSE Health, London School of Economics and Political Science, London, UK

${ }^{\mathrm{b}}$ European Institute, London School of Economics and Political Science, London, UK

Working Paper No. 19/2010

First published in October 2010 by:

LSE Health

The London School of Economics and Political Science

Houghton Street

London WC2A 2AE

(C) Nebibe Varol, Joan Costa-Font, Alistair McGuire

All rights reserved. No part of this paper may be reprinted or reproduced or utilised in any form or by any electronic, mechanical or other means, now known or hereafter invented, including photocopying and recording, or in any information storage or retrieve system, without permission in writing from the publishers.

British Library Cataloguing in Publication Data

A catalogue record for this publication is available from the British Library

ISBN [978-0-85328-460-4]

Corresponding Author

Nebibe Varol

LSE Health

Cowdray House

London School of Economics and Political Science

Houghton Street

London WC2A 2AE

Email: n.varol@1se.ac.uk 


\begin{abstract}
This paper investigates how regulation impinges on the launch strategies of international pharmaceutical corporations for new molecules and generics across the main OECD markets during 1960-2008. Comprehensive IMS data is used to analyze the international diffusion of 845 molecules from 14 different anatomic therapeutic categories using non-parametric survival analysis. The paper focuses on two main regulatory changes that reshaped the barriers to entry substantially: the US Hatch-Waxman Act in 1984 and the establishment of the European Medicines Agency (EMA) in 1995. We find that legal transaction costs have a significant impact on timing of launch. Stringent market authorization requirements for new pharmaceutical products in the US after 1962 resulted in a significant US drug lag in the introduction of pharmaceutical innovation vis-à-vis Europe during 1960-1984. However, financial incentives of the 1984 Hatch-Waxman Act proved effective in closing this lag. A more streamlined EMA regulatory approval process has reduced barriers to entry in Europe enabling quicker diffusion of pharmaceutical products, yet a marked pattern of delay in adoption of innovation is still evident due to local differences in pricing regulations. New molecule launch strategically takes place first in higher-priced EU markets as a result of threat of arbitrage and price dependency across the member states. Finally, the impact of price controls on the launch timing of pharmaceutical innovation translates to the adoption of imitative pharmaceutical products-hampering access not only to new technologies but also to cost-saving substitute products.
\end{abstract}

Key words: international drug launch, drug lag, pharmaceutical regulation. 


\section{Contents}

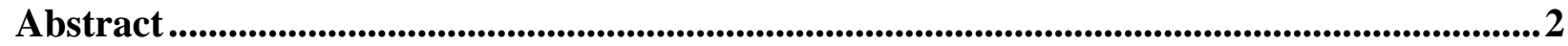

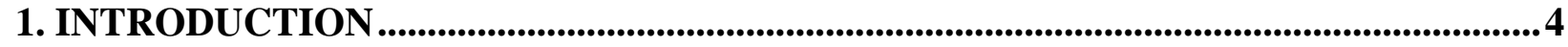

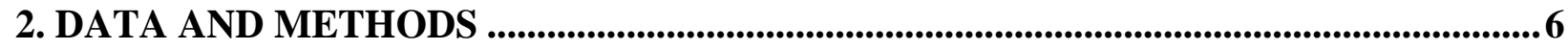

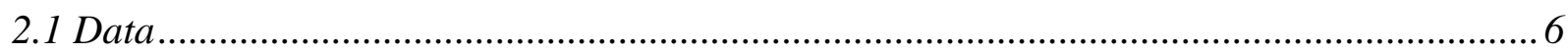

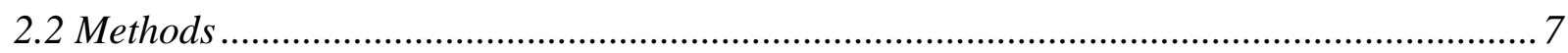

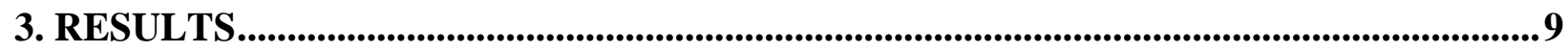

3.1 Trends in the Adoption of Pharmaceutical Innovation ....................................................... 9

3.2 Trends in the Adoption of Generic Products....................................................................... 19

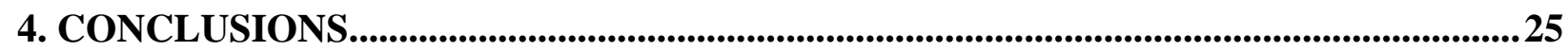

Acknowledgements.................................................................................................................................2

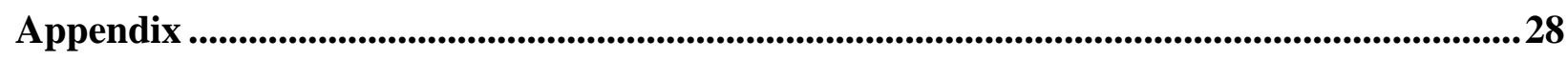

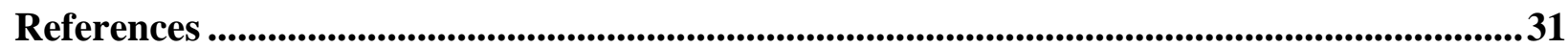




\section{INTRODUCTION}

The purpose of this paper is to investigate how the regulatory environment impinges on the launch strategies of pharmaceutical corporations across the main OECD markets during 19602008. How regulation affects adoption of innovation is a question open to empirical scrutiny, especially in highly regulated industries such as the pharmaceutical industry where products and processes are protected by intellectual property rights. Although several studies have been carried out, the existing evidence in the pharmaceutical context is limited. Particularly important is the role of the timing of new drug launch, which is typically carried out by international companies following some corporate strategy. Paradoxically, the impact of regulation on generic products within a therapeutic group has received even less attention. Expected proliferation of bioequivalent products in the near future, rising concerns over cost containment and the resulting push for genericization makes timing of generic launch a question of interest both for the pharmaceutical industry and the policy makers.

Normally, firms facing a competitive environment would like to launch new chemical entities (NCE) as quickly as possible into several markets while the product is still under patent protection to amortize the substantial R\&D outlays. However, there are at least two regulatory hurdles that firms have to overcome before commercializing a new drug product. The first hurdle is that manufacturers have to prove the threefold requirement of quality, safety and efficacy of new molecules which is estimated to take around ten years of pre-clinical and clinical research (Permanand 2006). The second hurdle typically includes the review of the new product dossier by the regulatory authority (FDA ${ }^{1}, \mathrm{EMA}^{2}$ or any national authority) and approval of marketing authorization (MA). Finally, the third hurdle following marketing approval is pricing and reimbursement $(\mathrm{P} \& \mathrm{R})$ which involves negotiations between manufacturers and $\mathrm{P} \& \mathrm{R}$ authorities regarding the price of the new product and its reimbursement status. Price regulation can arguably delay launch through the negotiation processes alongside the resulting firm strategies of delaying or foregoing launch in low-priced markets ${ }^{3}$ (Danzon, Wang et al. 2005; Kyle 2007). Non-homogeneity in these hurdles across markets results in launch delays, with welfare implications for the consumer and the pharmaceutical producer.

Lags in adoption of new pharmaceutical innovations may affect consumer welfare through impaired access to new drug products, in particular cost-effective products. Empirical evidence shows that lack of access to new drugs leads to compromises in health outcomes (Schoffski 2002), shifts volume to older molecules of lower therapeutic value (Danzon and Ketcham 2004)

\footnotetext{
${ }^{1}$ Food and Drug Administration

${ }^{2}$ European Medicines Agency (www.ema.europa.eu)

${ }^{3}$ The US, UK and Germany do not require price approval; however, in the UK, Germany and several other markets cost-effectiveness evaluation may further delay the adoption of new pharmaceutical innovation as the fourth hurdle
} 
and results in higher expenditures on other forms of medical care and compromises in quality of health care (Kessler 2004; Wertheimer and Santella 2004). Innovative medications offer economic benefits through fewer work days missed and lives saved (Lichtenberg 1996; Lichtenberg 2003; Hassett 2004; Lichtenberg 2005). Delays in the launch of new molecules could be costly to the pharmaceutical industry through reduced market exclusivity periods, lower returns to $R \& D$ and eventually fewer innovations ${ }^{4}$.

Generic products are by definition bioequivalent, and therefore perfect substitutes (on objective quality grounds), to their branded counterparts that usually claim substantial price mark-ups over the marginal cost of production ${ }^{5}$. Generic entry following patent expiry is argued to enhance efficiency and competition in the drug market; however, the main hurdle before generic entry is the cost of bioequivalence tests which have been estimated to be significantly cheaper than the average costs of safety and clinical evaluation ${ }^{6}$. Generic imitations largely free-ride on the R\&D efforts of originator firms, which enables them to compete solely based on price. Timely adoption of generic products, therefore, carries significant importance to improve allocative efficiency and stimulate competition (DG Competition 2009).

The analysis in this paper draws upon an extensive database on the timing and entry of new pharmaceutical molecules along with the entry of bioequivalent competitors. The paper has several contributions to the literature on regulation and changes in corporate behaviour. First, data used in previous studies is mainly restricted to specific, small time periods. Second, one of the most important dimensions of market dynamics, the timing dimension of new and old products, has been traditionally left out of the analysis of drugs. Finally, the paper assesses corporate behaviour with respect to two main regulatory changes that reshaped the barriers to entry substantially: 1) the US Hatch-Waxman Act in $1984^{7}$; 2) the establishment of the European Medicines Agency (EMA) in 1995 along with the adoption of the centralized procedure that grants a Community marketing authorization.

The organisation of the paper is as follows: Section 2 describes the data and methods used in the analysis; Section 3 discusses the results of the analysis along with corresponding regulatory triggers; and finally Section 4 concludes.

\footnotetext{
${ }^{4}$ Both profit expectations and lagged cash flows have been shown to have significantly positive impacts on pharmaceutical firms' R\&D investment intensity (Vernon 2005)

${ }_{5}^{5}$ A generic is defined by the European Directive 2004/27/EC as "a medicinal product which has the same qualitative and quantitative composition in active substances and the same pharmaceutical form as the reference medicinal product, and whose bioequivalence with the reference medicinal product has been demonstrated by appropriate bioavailability studies."

${ }^{6} 18$ times cheaper according to the Pharmaceutical Manufacturers Association (Pharmaceutical Manufacturers Association 1993)

${ }^{7}$ The cut off value of 1984 has been suggested as a pivotal year in the history of drug introduction patterns between the US and the UK (Coppinger, Peck et al. 1989)
} 


\section{DATA AND METHODS}

\subsection{Data}

The IMS data used in the analysis contains quarterly sales in dollars and standard units for molecules from 14 different ATC groups and 20 countries $^{89}$. Additional data fields include global and local launch date of drug products, pharmaceutical form, anatomic therapeutic class of the product, the distribution channel of sales (hospital vs. retail), and patent protection status of the drug. The markets in the dataset comprise the majority of the global pharmaceutical sales and are all based in the OECD except for South Africa. Results are reported for the main seven pharmaceutical markets comprised of the US, Japan and the EU5 (namely the UK, Germany, France, Italy, and Spain).

Multi-country drug lag studies apply several criteria to identify significant NCEs. Some consider molecules that have launched in the US and/or the UK as an indication of therapeutic significance and potential for global launch (Parker 1984; Danzon, Wang et al. 2005). Several studies find a direct relationship between the therapeutic contribution of a new drug and its likelihood of achieving widespread introduction (Parker 1984; Barral 1985). This finding suggests that most one-market new chemical entities (NCEs) do not simply disperse among countries more slowly than others, but that they are never going to be widely available due to their marginal therapeutic advantages. Molecules that have not launched in the US and the UK are excluded to avoid any potential bias due to one-market molecules and to ensure that molecules with potential global importance are considered. Hereafter, this potentially global set of molecules is referred as US\&UK molecules.

In addition, a global molecule set comprised of molecules that have diffused to all twenty markets on the database is defined. These two sets provide a means to compare relative drug lags for molecules with different levels of international spread and to assess whether there exists a systematic difference between the two. For brevity, the results for US\&UK molecules only are reported. Findings for global molecules are broadly in line with the estimates for US\&UK molecules.

Table 1 presents the breakdown of molecules by the period of global launch. The majority of the molecules had their global launch during 1960-1984. In total 845 molecules were launched in the US and UK since 1960, 200 of which diffused to all markets. Only 350 of the molecules had a

\footnotetext{
${ }^{8}$ IMS (Intercontinental Medical Services) MIDAS data was collected at Merck Sharp and Dome Limited (MSD) premises in Hoddesdon, UK.

${ }_{9}^{9}$ Australia (ALIA), Austria (AUS), Belgium (BEL), Canada (CAN), Finland (FIN), France (FRA), Germany (GER), Greece (GRE), Italy (ITA), Japan (JAP), Netherlands (NET), Poland (POL), Portugal (POR), South Africa (SAF), Spain (SPA), Sweden (SWE), Switzerland (SWI), Turkey (TUR), the UK, and the US
} 
generic launch both in the US and UK. The US, UK, Germany, France, Canada and Switzerland are among countries that had the greatest number of launches whereas Portugal, Japan, Spain, Belgium, Sweden and Turkey had the least number of launches. The highest number of generic molecule launches occurred in the US, UK, Germany, Canada, Poland, Australia and Netherlands.

Table 1 Number of Molecules by Period of Global Launch

\begin{tabular}{|l|c|c|}
\hline & $\begin{array}{c}\text { US\&UK } \\
(\text { All })\end{array}$ & $\begin{array}{c}\text { US\&UK } \\
\text { (Generic) }\end{array}$ \\
\hline$[60-84)$ & 385 & 214 \\
\hline$[84-95]$ & 194 & 90 \\
\hline$[95-08]$ & 266 & 46 \\
\hline TOTAL & 845 & 350 \\
\hline
\end{tabular}

\subsection{Methods}

Launch times are the most important information to feed a non-parametric survival analysis. The advantage of nonparametric approaches lies in that it provides a good fit for any distribution without any prior assumptions about the functional form of the failure time. The analysis takes place at the molecule level, whereby subjects are defined as potential molecule-country launches. The failure event is interpreted as the launch of a given molecule in the destination market. The failure indicator is set to one if the molecule launches in the given market and to zero if the molecule is censored (i.e. does not launch by the end of the observation period 2008) ${ }^{10}$.

The time to failure event is defined as the time lapse from the first global launch date of the molecule (the onset of risk) to the date of launch in a particular country (the failure). The global launch date is the first date the molecule launched in any country in the IMS database. Since drug products may differ with respect to the local launching corporation, dosage, and form, the local launch date of each molecule is defined as the minimum launch date among drug products of the same molecule in individual countries. Missing global launch dates are proxied by the minimum local launch date across all twenty markets. Relative launch lags are defined as the difference between the global launch date and the country-specific local launch date ${ }^{11}$. Differential timing of launch could be due to variations in market authorization dates or delays in pricing and reimbursement procedures as well as strategic firm delays to avoid threats of price spillovers across markets (Danzon, Wang et al. 2005). The global launch date is used to define

\footnotetext{
${ }^{10}$ For global molecules right-censoring is not an issue since the exact launch time of every molecule is known in all countries.

${ }^{11}$ Spain, Turkey, Belgium, Greece, Portugal, Spain, South Africa have only retail channel data; therefore, the first local launches in these countries represents launch in the retail sector.
} 
the onset of risk for molecule launches due to unavailability of data to isolate the delays due to these components.

The risk onset in the case of pharmaceutical imitation is defined as the date when the first generic product of a given molecule launched in any of the twenty markets. It would have been informative to carry out the analysis by considering generic delays following the local protection expiry dates. This approach was not followed because expiry date is available only in $3 \%$ of the data and in $56 \%$ of these cases expiry date exceeds local launch by more than a year, which could be due to the presence of copy products in some markets, launch of pseudogenerics ${ }^{12}$ (also known as authorized generics) or errors in reporting the expiry dates.

\subsubsection{Non-parametric Kaplan-Meier Estimates}

The survivor function estimate $\hat{S}(t)$, the probability that the subject fails beyond time $t$, is estimated by (Kaplan and Meier 1958):

$$
\hat{S}(t)=\operatorname{Pr}(T>t)=\prod_{j \mid t_{j} \leq t}\left(1-\hat{p}_{j}\right)=\prod_{j \mid t_{j} \leq t}\left(\frac{n_{j}-d_{j}}{n_{j}}\right)
$$

where $p_{j}=\operatorname{Pr}\left(t_{j-1}<T \leq t_{j} \mid t_{j-1}<T\right)$ is the conditional probability that the subject fails within the interval $\left[t_{j-1}, t_{j}\right) . n_{j}$ is the number of subjects at risk, $d_{j}$ is the number of failures at time $t_{j}$ and $t_{1}, t_{2}, \ldots t_{k}$ are the observed failure times. The estimate of the survival function is given as the product of conditional survival probabilities over all observed failure times (i.e., countrymolecule launches) less than or equal to time $t$.

The standard error for the Kaplan-Meier estimate $\hat{S}(t)$ is given by Greenwood's formula:

$$
\operatorname{Var}(\hat{S}(t))=\hat{S}^{2}(t) \sum_{j \mid t_{j} \leq t} \frac{d_{j}}{n_{j}\left(n_{j}-d_{j}\right)} .
$$

Kaplan-Meier estimates of the survivor function $S(t)$ at time $t$ are obtained using Stata 10. The median survival time corresponds to the smallest time point at which the survivor function is less than or equal to $0.5(\hat{S}(t)=0.5)$, i.e. the time point at which half of the molecule candidates have launched. Mean survival time, on the other hand, is estimated as the area under the survival curve. Due to the significant right-skewed nature of failure time distributions inferences are

\footnotetext{
${ }^{12}$ Pseudogenerics are generics marketed by brand-name companies to compete against independent generics
} 
based primarily on the median delays. The median survival times are estimated in each market for molecules by period of entry into the risk set, i.e. first global launch during 1960-1984, 19841995 and 1995-2008. This framework allows the comparison of the evolution of relative launch lags both across countries and over time. Since the cut-off points of 1984 and 1995 correspond to two major regulatory changes in the US and Europe, their impact on timing of launch can be assessed comparatively using medians before and after these cut-off values.

\section{RESULTS}

\subsection{Trends in the Adoption of Pharmaceutical Innovation}

\section{Evolution of Median Delays over Decades}

Figure 1 shows the trend in overall median delays for US\&UK molecules across the twenty markets from 1960 to 2008. A marked acceleration in the international diffusion speed of pharmaceuticals is observed. While the overall median is 11 years for molecules with a global launch in 1960-1985, the median drops to 4 and 2 years for molecules that launched in 19841995 and 1995-2008 respectively (see Table A.1 in the Appendix for the medians in individual countries over time). The significance of this trend is tested by a Cox proportional hazard model that controls for the period of global launch. Coefficients are estimated both by a Cox model with country fixed effects and a random effects Cox model with shared frailties for the same country launches. Both the fixed effects and the random effects indicate that hazard of launch ${ }^{13}$ is significantly higher for molecules that first launched during 1995-2008 compared to 19841995. Similarly, the hazard is higher for molecules that launched in 1984-1995 compared to 1960-1984. The Hausman test that compares the fixed and random effects specifications indicates that the fixed effects model is the correct specification (p-value: 0.0135). Based on the fixed effects specification launch in 1960-1984 decreases the hazard by 48\% and launch in 1995 2008 increases the hazard by $82 \%$, both compared to launch in 1984-1995.

\footnotetext{
${ }^{13}$ The instantaneous probability of launch conditional on not launching before
} 
Figure 1. Overall median delays with respect to period of global launch

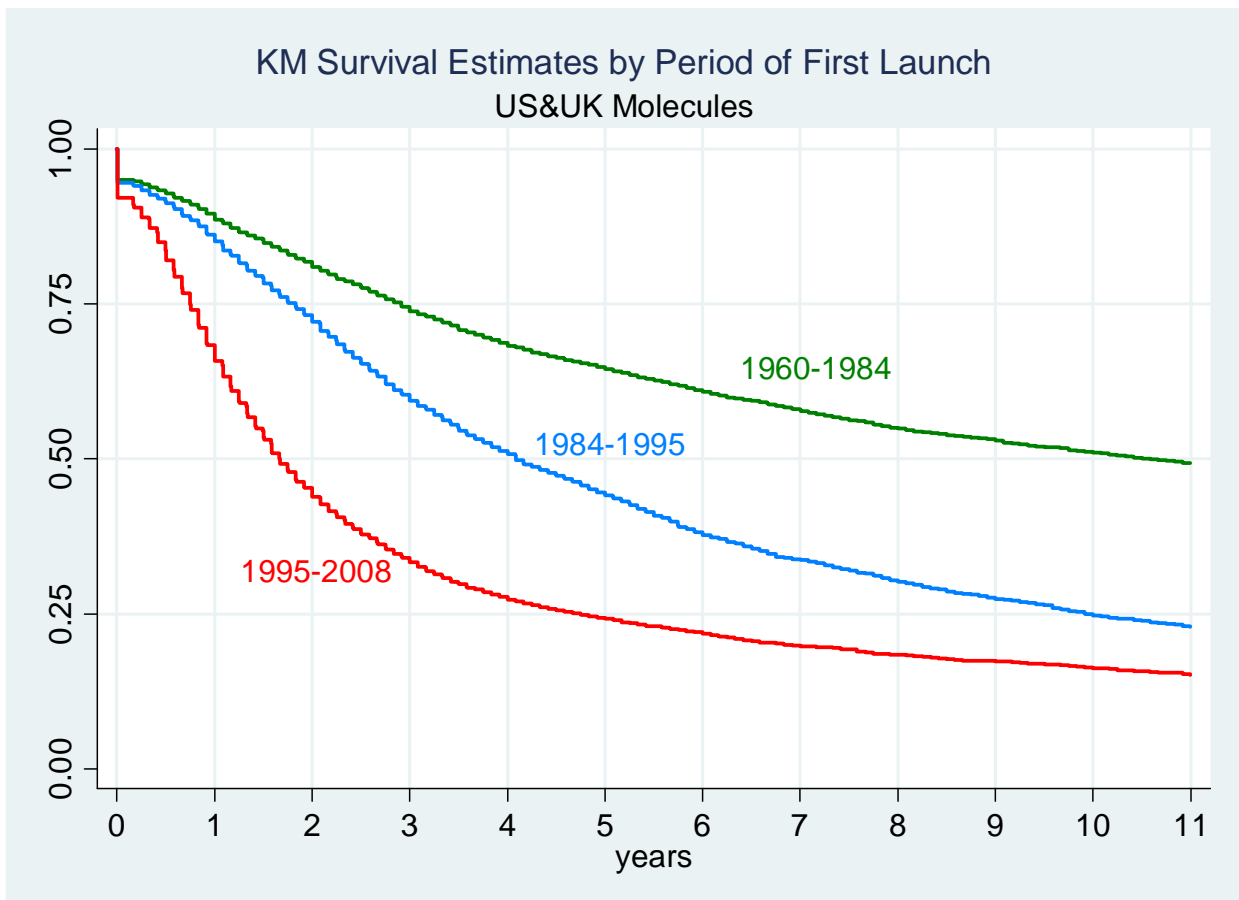

The acceleration of the international diffusion of pharmaceutical products may be attributed to the evolution in barriers to entry as a result of changes in the regulatory environment and an increasingly global and interdependent market environment. The increasing international reach of pharmaceutical corporations as evidenced by the spread of the manufacturing, marketing and innovative R\&D activities to different countries has overcome prior geographical barriers. Harmonization of safety and efficacy and marketing authorization requirements across markets has contributed to a reduction in regulatory costs (Busfield 2003). The following sections present the survival estimates for individual markets in the biggest seven pharmaceutical markets and describe in more detail the regulatory changes that may explain the evolutionary trend in the lags.

\subsubsection{0-1984: Stringency in MA Regulations and the US drug lag}

The Thalidomide tragedy in the late 1950s, which caused congenital anomalies in babies and a degenerative nerve disorder in pregnant women, marked the beginning of a new era in modern medicine regulation. Until the early 1960s most countries except the Nordic countries and the US had no independent safety and efficacy protocols for new drugs. The US had a regulatory office for pharmaceuticals, the FDA, which was empowered to license medicines subject to certain safety standards. US drug companies had to show only the safety of their new products before 1960. However, in1962 the US Kefauver Harris Amendments introduced an additional proof-ofefficacy requirement as a response to the Thalidomide disaster. Other countries in Europe 
aligned their marketing authorizing procedures for increased safety and efficacy only in late 1960s and early 1970s (Permanand 2006).

The debate about launch delays extends back to 1960s when the main concern was the significant US drug lag compared to the main EU markets, mainly as a result of the more stringent US regulations. Wardell, a pharmacologist, coined the term "drug lag" and increased awareness of the unavailability of new drugs in the US, and stressed that the delay affected therapeutically important drugs as well (Wardell 1973; Wardell 1974; Wardell 1978). Later studies by Grabowski (1980), Berlin and Jonsson (1986) and Kaitin (1989) confirmed findings of Wardell (Grabowski 1980; Berlin and Jonsson 1986; Kaitin, Mattison et al. 1989).

The survival estimates in this study for molecules that launched first during 1960-1984 confirm findings of the early literature that the US market was relatively disadvantaged for the timely adoption of pharmaceutical innovations as a result of much stricter requirements for regulatory approval. The survival graph in Figure 2 shows the probability that molecule launch in a given country occurs after $t$ years following global launch, conditional on the fact that the molecule has not launched in that country up to time $t$. Hence, it takes longer for countries with a higher survival curve to adopt new pharmaceutical innovations. The median survival time, the time point at which half of the molecule candidates have launched, is given by the $t$ value where the survival probability is 0.5 .

Figure 2. Survival Estimates: 1960-1984

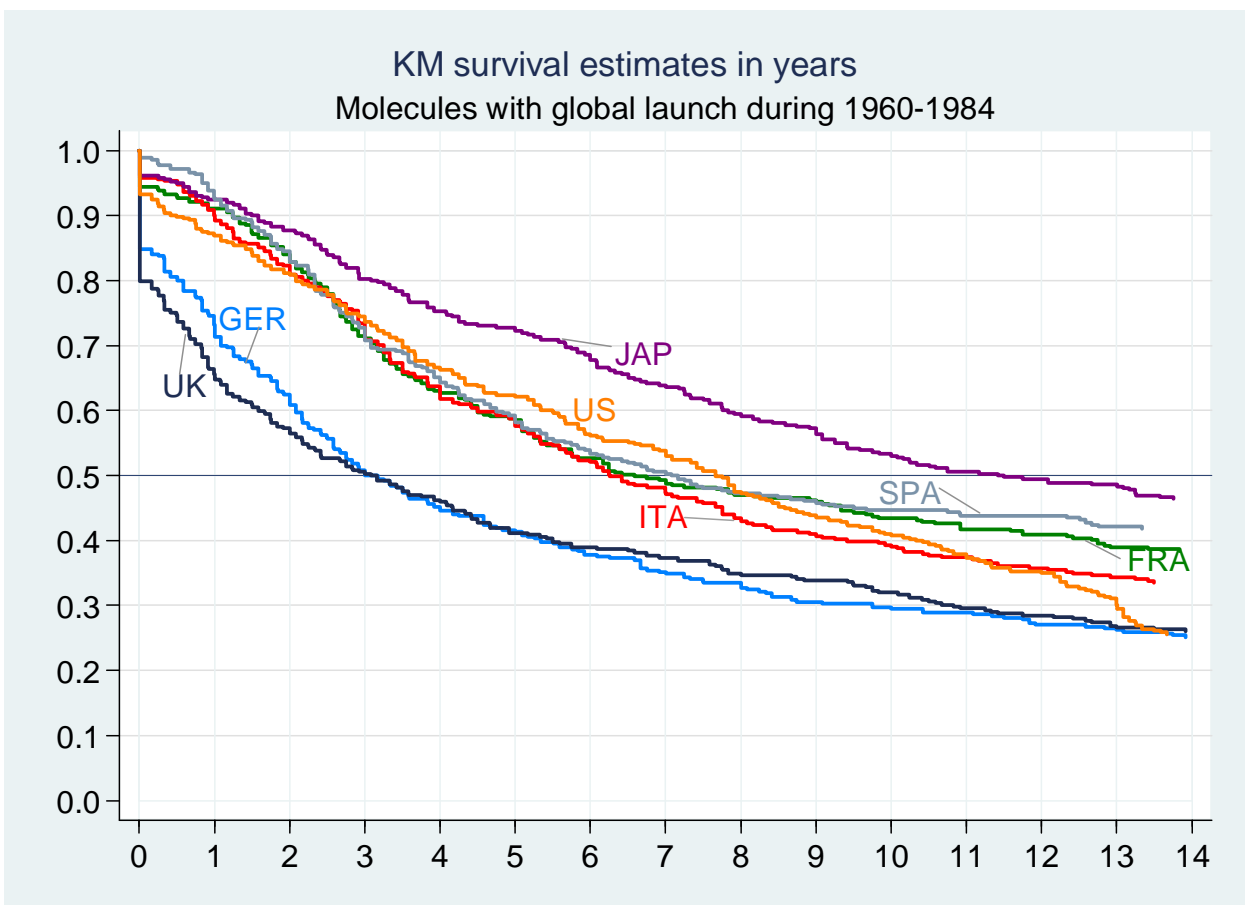


During 1960-1984, Europe is found to be leading in the introduction of pharmaceutical innovation. As expected, free price countries such as the UK and Germany are leading markets, with a median delay of 3 years and are followed by Italy, France and Spain with a corresponding lag of 3.5- 4 years. The US lags behind the slowest European market by about half a year. Japan has the most dramatic delay of 12 years, which can be attributed to geographical barriers and predominantly domestic nature of the market, especially in a period when the global expansion of pharmaceutical corporations was relatively limited.

\subsubsection{4-1995: The US Hatch-Waxman Act and Stimulus for Innovation}

The Hatch Waxman Act, also known as the Drug Price Competition and Patent Term Restoration Act of 1984, was enacted to compensate for the loss in effective patent life during drug development. The Act extended pharmaceutical patents for the time lost in clinical testing and regulatory review, but the entire patent term restored was restricted to 5 years and the term of the restored patent following FDA approval was restricted to 14 years. In addition, the Act introduced a five-year market exclusivity period for NMEs such that once an NME is approved a generic manufacturer cannot submit an application until 5 years after the approval of the pioneer and thus cannot enter the market for at least 5 years. These amendments enabled pharmaceutical innovators to recoup some of the revenue losses due to regulatory stringency after 1962. The main aim of the Act, however, was to maintain incentives for innovation while ensuring quick generic entry. Although the impact on the brand-name drugs is somewhat contentious, data from the literature suggests that stimulation for innovation resulted in increased R\&D funding and R\&D intensity (Branes 2007).

Figure 3. Survival Estimates: 1984 - 1995

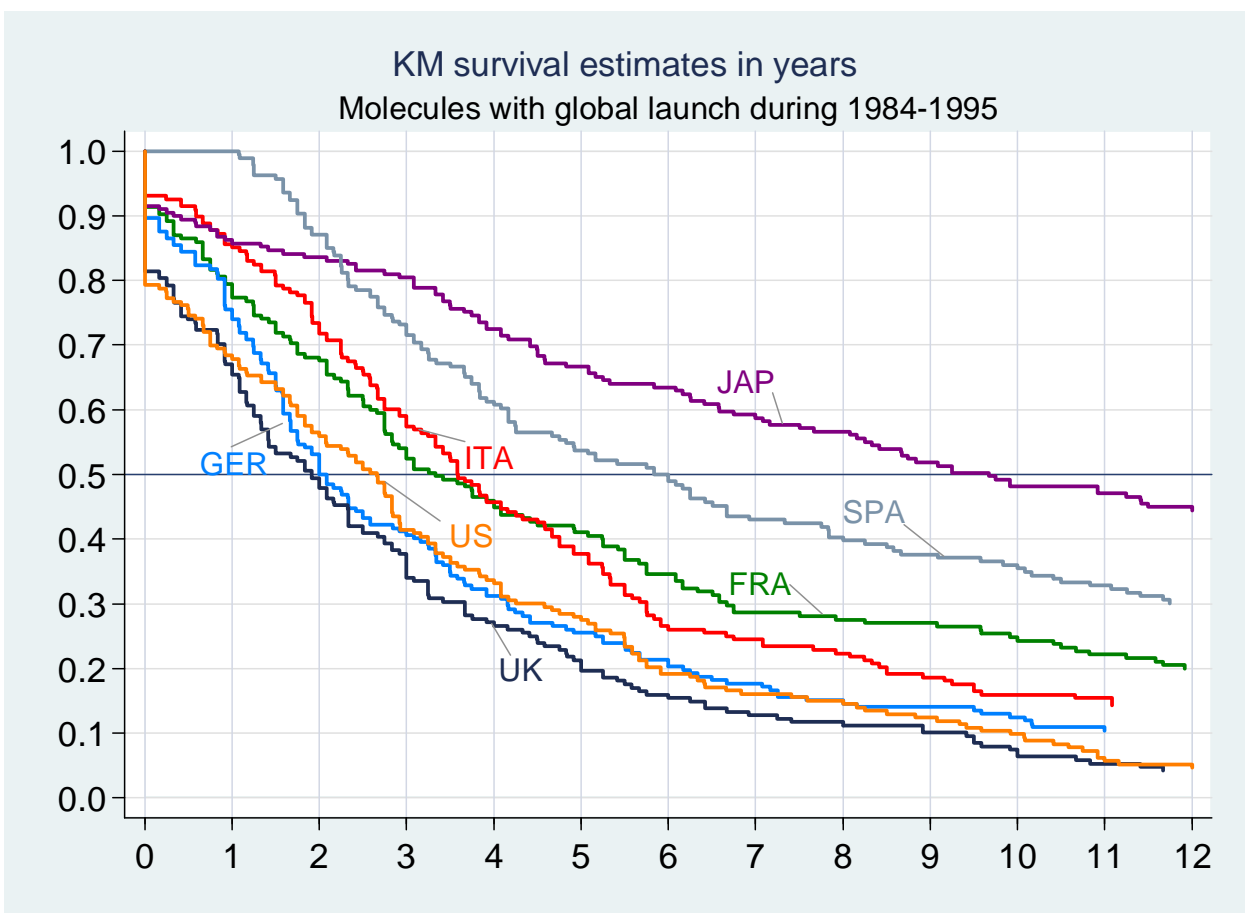


Survival estimates in this study indicate a stark improvement in the US for the timing of new product launches vis-à-vis Europe (Figure 3). The median delay in the US decreased from about 8 years to 3 years following the enactment of the Act whereas the corresponding decrease in the leading markets of UK and Germany was on the order of one year only. While the US was the second slowest market to adopt new pharmaceutical molecules in 1960-1984, after the 1984 Act the US becomes one of the leading markets along with the UK and Germany. The estimates present a clear indication that the 1984 Act has generated a more favourable environment for market entry in the US and suggests an increase in overall R\&D activity in the US pharmaceutical industry.

The remaining markets in Europe also experience faster introductions after 1984. In particular, the medians in France and Italy decrease by 3 years (to about 3.5 years). The one-year reduction in the Spanish median delay is more modest and can be partially attributed to the lack of product patent protection for new pharmaceuticals before ratification of the TRIPS Agreement in 1995. Overall, Spain and Japan emerge as the slowest adopters following the 1984 Act. Local clinical trial requirements are the core factor for the Japanese drug lag and the exclusion of foreign corporations from the Japanese market. According to a study that analyzes the Japanese lag during 1981-1993, the second influential factor is the price regulations since 1981 that sharply lowered launch prices and the life cycle sales of drugs launched into Japan (Thomas 2001).

Patent term restoration in Europe was enacted only eight years following the 1984 Act in the US. In 1992, Supplementary Protection Certificate (SPC) extended the protection period of pharmaceutical products in the European Community (EC) by 5 years following patent-expiry or 15 years of protection from the date of first market authorization in the EC, instead of twenty years after patent application as under the European Patent Convention ${ }^{14}$. This prolonged the profit life of products as drug sales are generally highest during the period of market exclusivity. In addition, the SPC prevented generic companies from engaging in R\&D prior to patent expiry, which essentially ensured a longer shelf-life for branded products and provided stimulus for innovation. The relative delay in providing financial stimulus for innovation through patent term restoration in the EU could be an additional factor that explains the drastic improvement in the timing of new product launches in the US vis-à-vis Europe during 1984-1995.

\subsubsection{5-2008: EMA and Harmonization across the Globe}

The set up of a single market in 1993 and a common currency in 1999 (when exchange rates were pegged) ensured free movement of people, goods and services within the EU. Since then

\footnotetext{
${ }^{14}$ The SPC became effective on Jan 1993 and applied to drugs granted market authorization in the EU after Jan 1985.
} 
market authorization has been streamlined by the establishment of the European Medicines Agency (EMA) in 1995 although a complete harmonization of the pharmaceutical market has not taken place. This was a significant step to speed approval times across Europe which had begun to suffer from increasing number of applications as the industry grew and technical and scientific issues became more complex. In addition, EU Directive 2004/27/EC introduced a uniform level of data protection for 10 years across the EU and precluded the launch of the generic copy until the expiry of the 10-year period.

A centralized approval procedure, which grants a Community-wide authorization valid in all Member States, would increase efficiency by obviating the duplication of effort through a single market authorization process and saving an annual expenditure of $\$ 350 \mathrm{~m}$ by drug firms to get separate approvals from individual member countries (Annon 1994). The centralized procedure, however, does not apply to all products. It is mandatory for all biotechnology processes and optional for innovative chemical drugs provided the product offers a significant therapeutic, scientific or technical innovation ${ }^{15}$.

After 1990, the pharmaceutical industry witnessed further harmonisation efforts. The Agreement on Trade Related Aspects of Intellectual Property Rights (TRIPS) in 1994 strengthened intellectual property rights and provided significant financial incentives for companies by blocking generic competition until the expiry of the 20 years patent life and by extending the scope of patent protection both to products and processes (WTO OMC 2003). Similarly, the International Conference on Harmonisation of Technical Requirements for Registration of Pharmaceuticals for Human Use (ICH) has aimed to achieve greater harmonisation in the application of technical guidelines and requirements for product registration across the EU, US and Japan to reduce or obviate the need of duplicative testing in the R\&D stage ${ }^{16}$.

Figure 4 shows that the median delays continued to decrease throughout 1995-2008 as a response to the harmonization efforts across the biggest 7 pharmaceutical markets, yet the differential delays have not been eliminated totally ${ }^{17}$. Most of the molecules launch immediately in the US followed by launch in the free-priced European markets of Germany and the UK within one year. The US emerges as the most favourable market because of high profit potentials. This is both because the US has the largest market size and a more liberal pricing environment compared to other OECD markets that employ some form of price control, either in the form of statutory pricing whereby the price is set on a regulatory basis or through price negotiations (Vogler 2008). Stringent price controls have been criticized for having negative

\footnotetext{
${ }_{16}^{15} \mathrm{http}: / /$ www.emea.europa.eu/

${ }^{16} \mathrm{http}: / /$ www.ich.org

${ }^{17}$ Log-rank test for equality of survivor functions indicate that the difference in median delays between countries is significant (p-value: 0.0000). In addition, significant heterogeneity exists with respect to the ATC group (p-value: 0.0021), which implies that the relative delays vary across ATC groups.
} 
implications on the extent and timing of launch via knock-on effects on foreign markets through external referencing and parallel trade within the EU; however, the available evidence is limited (Danzon and Epstein 2005; Kyle 2007; Danzon and Epstein 2008).

Figure 4. Survival Estimates: 1995-2008

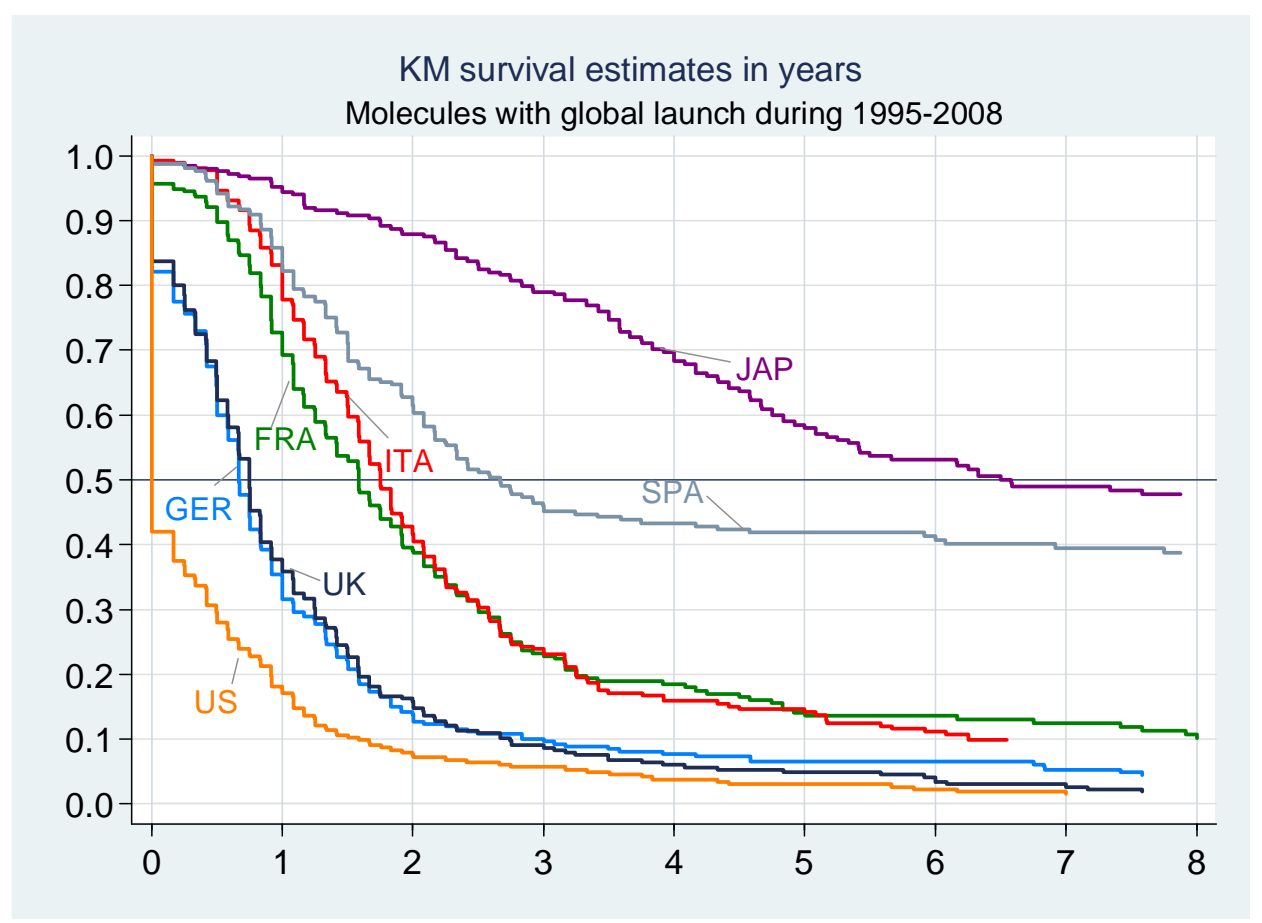

The relative launch delays in Europe suggest an ordering with respect to price levels of pharmaceutical products. Figure 5 illustrates the correlation between median delays and the bilateral price indexes with respect to US prices for $2004^{18}$. The correlation is -0.47 and is significant at the 0.01 level. France and Italy seem to have a comparable speed of launch with a median delay of around two years. The median lag in Spain has decreased compared to 19841995 but it still lags about a year behind France and Italy. The lack of product patent protection for new pharmaceuticals before EU membership contributes to launch delays in Spain. EU accession in 1986 required Spain to comply with the European Patent Convention (EPC), which allowed the patentability of both products and processes. Spain enacted a new patent law in 1986 which introduced patent protection for pharmaceuticals. However, effective patentability was delayed until 7 October 1992 through Reservation under Article 167 of the EPC, which essentially meant that pharmaceutical and chemical products could not be patented in Spain prior to 7 October 1992. In 1995, Spain ratified the TRIPS Agreement, which substantially changed

\footnotetext{
${ }^{18}$ Bilateral price indexes are calculated by considering common molecules in the US and the respective country, prices are weighted by the US Volume
} 
the patent protection landscape ${ }^{19}$. In addition, Spain is one of the major parallel exporters in the EU due to its relatively lower drug prices, which are further pushed downwards by unilateral price cuts imposed on pharmaceutical prices. The delay in Spain, therefore, is consistent with pharmaceutical firm strategies to avoid parallel trade (Kyle 2007).

Figure 5. Bilateral Price Indexes with Respect to US Prices vs. Median Delays (for ethical branded products in the retail sector)

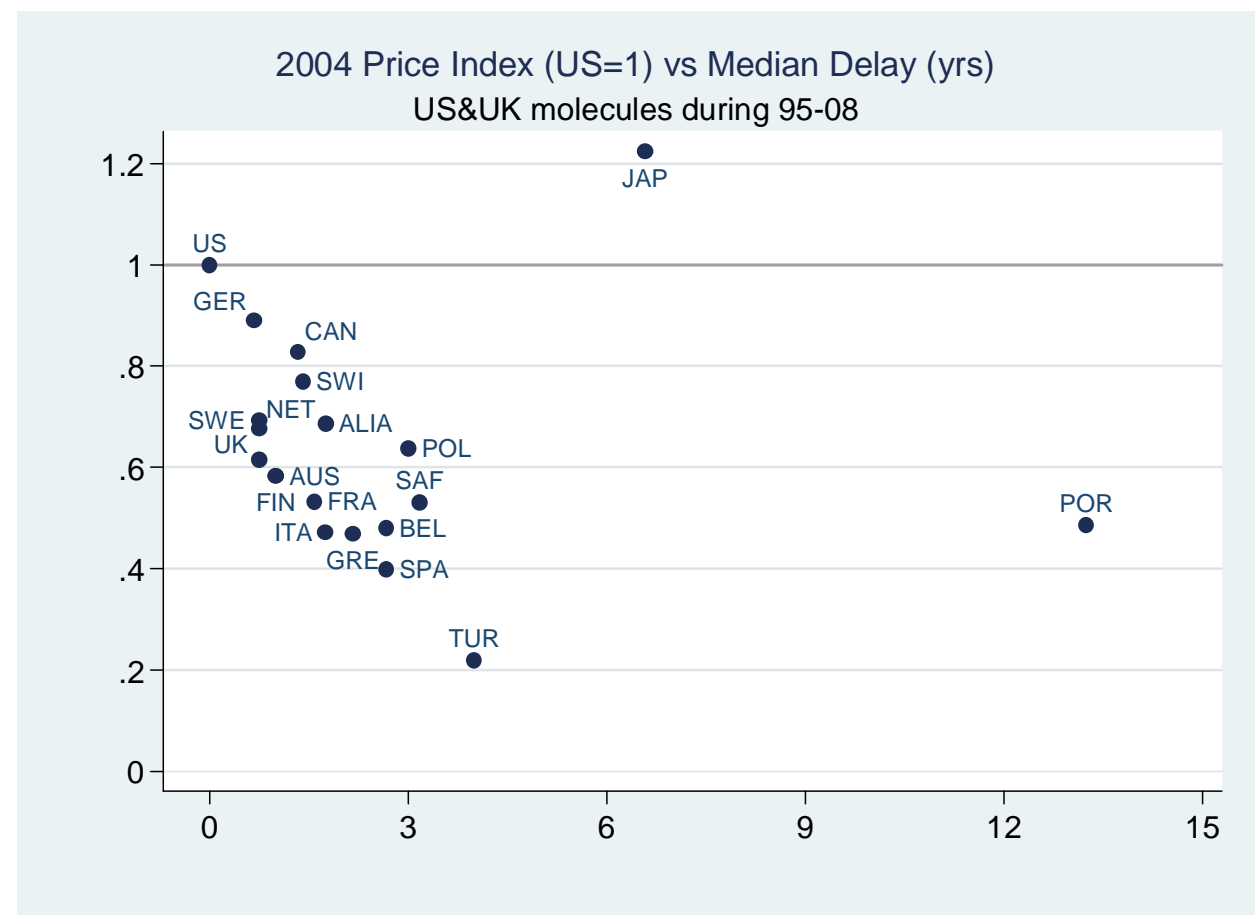

Note: Bilateral price indexes are calculated by considering common molecules in the US and the respective country, prices are weighted by the US Volume ${ }^{20}$

The Japanese drug lag extends to this period as well although the median Japanese delay decreases by two years with respect to the previous period. This is paradoxical given the international competitiveness of numerous Japanese high-tech industries including electronics and automobiles during 1990s. The Japanese pharmaceutical market is the second largest market in the world and offers a great profit potential because of a large market size and relatively high

19

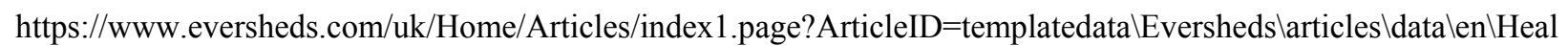
thcare $B$ BioBrief_Stop_press_Direct_applicability_in_Spain_of_patent_provisions_of_the_TRIPS_Agreement

${ }^{20}$ ALIA: Australia; AUS: Austria; CAN: Canada; FIN: Finland; FRA: France; GER: Germany; GRE: Greece; ITA: Italy; JAP: Japan; NET: Netherlands; POL: Poland; POR: Portugal; TUR: Turkey; SAF: South Africa; SPA: Spain; SWE: Sweden; SWI: Switzerland 
drug prices (see Figure 5). Nevertheless, the Japanese pharmaceutical industry still remains predominantly domestic and uncompetitive.

Japanese regulations for new drug approval have required Japanese clinical data for evaluating the efficacy and safety of the drug even if foreign clinical data is available due to racial and ethnic variations in responses to medicines. In the past, all three phases of clinical trials had to be carried out on the Japanese population, which has driven launch delays in addition to other factors such as language barriers and longer times for patient enrolment in clinical trials. In 1998, Japan adopted the ICH E5 guideline entitled "Ethnic Factors in the Acceptability of Foreign Clinical Data" that recommends the use of foreign clinical data for new drug approval if there is one additional bridging study ${ }^{21}$ showing that the drug will behave similarly in the Japanese population. According to Uyama et al. (2005) new drug approvals based on a bridging strategy in Japan have increased from 3.2\% in 1999 to 25\% in 2003. Tabata and Albani (2008) report that companies are increasingly trying to leverage their operations globally in order to take advantage of the Japanese efforts to comply with the trend for globalising clinical trials (Tabata and Albani 2008). These developments suggest that the drug lag in Japan can decrease over the next years (Uyama, Shibata et al. 2005).

Ranking countries by median lags, countries may be characterised as leaders (the US, UK, Germany, Sweden, Netherlands, Finland, Austria, Switzerland) and laggards (Belgium, Greece, South Africa, Poland, Portugal, and Turkey). The remaining countries (France, Canada, Italy, Australia, and Spain) rank as intermediaries with the rank dependant on the period and extent of global launch. The laggards and leaders, as defined by countries with median lags above and below the overall delays, are similar for the global and the US\&UK molecules; however, the extent of the relative lag is shorter for the truly global molecules as is expected because global molecules have diffused to all markets and have non-censored survival times. Similarly, launch in all markets may indicate higher therapeutic or commercial importance at the product level.

\section{EMA Sub-Analysis}

Differences in the survival behaviour among the EU markets in Figure 4 indicate that pharmaceutical firms have adopted different launch strategies across markets in the EU and that efforts of harmonization in market authorization procedures have not eliminated the differentials in timing of launch across European countries. Sub-analysis for the EU countries ${ }^{22}$ is carried-out to further investigate the impact of the establishment of a centralized regulatory procedure in the

\footnotetext{
${ }^{21}$ A bridging study aims to confirm that the efficacy, safety and dose-response relationships of the drug in the new population are similar to those in the population evaluated in the foreign studies

${ }^{22}$ Austria, Belgium, Finland, France, Germany, Italy, Netherlands, Poland, Portugal, Spain, Sweden, UK
} 
EU. In order to compare relative delays for molecules that obtained centralized approval (central molecules) with those that did not (non-central molecules), data was collected for all centrally approved molecules from the EMA website (EMA publishes information following the grant of a Marketing Authorization as a European Public Assessment Report). This information was combined with the IMS database to estimate delays within the EU for molecules with a first global launch post-1995 (see Figure $6^{23}$ ).

Figure 6. Delays with respect to central vs. non-central approval in the EU

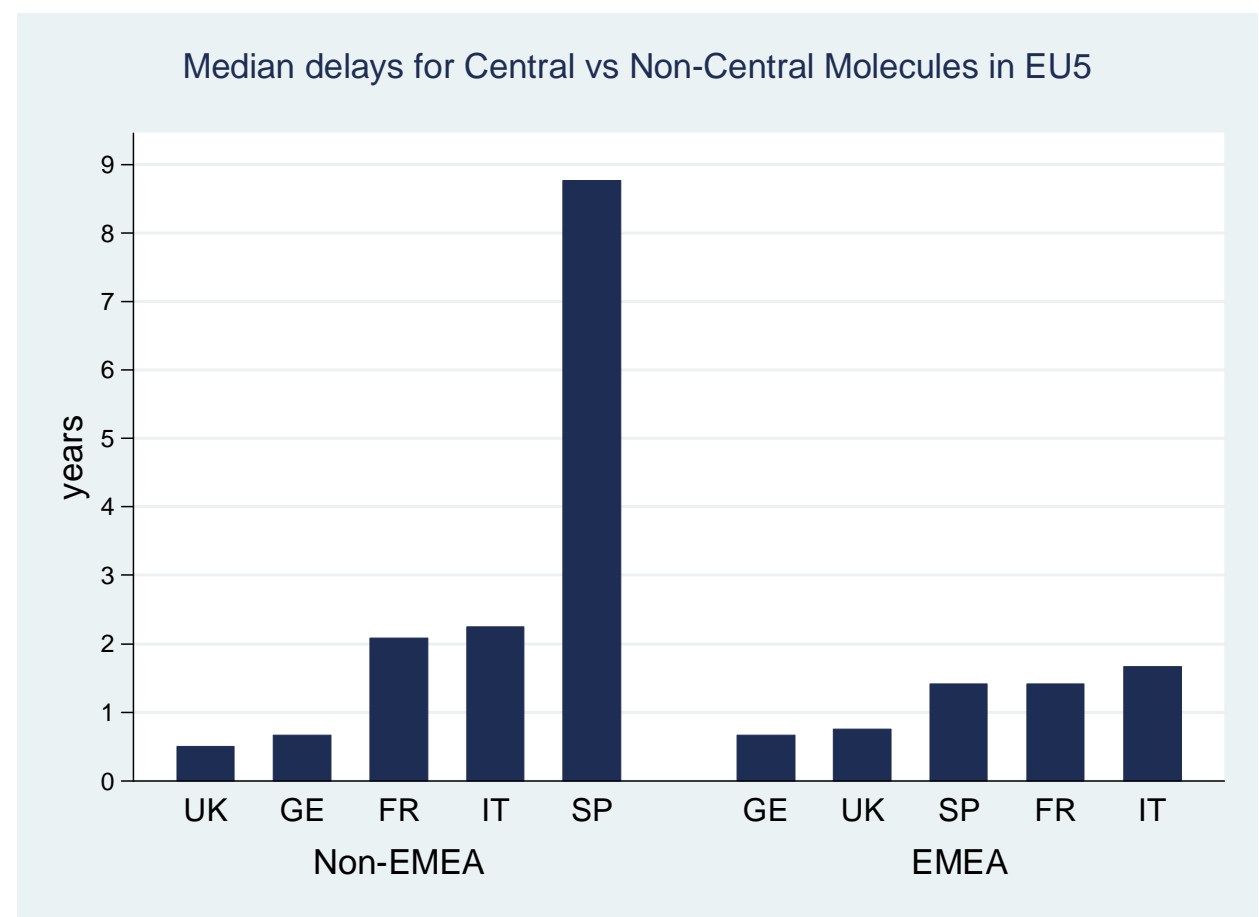

(Kaplan-Meier estimate for Spain not available, the restricted mean which provides a lower bound for the median is reported; EMEA: Molecules centrally approved by EMA)

There is a statistically significant difference in launch behaviours between the central and noncentral molecules ( $p$-value: 0.000 for the test of the null hypothesis that the survival behaviours of EMA and non-EMA molecules are identical). The effectiveness of a more streamlined authorization is demonstrated by the lower variation in launch timing for EMA molecules compared to molecules that did not go through the centralized procedure. The median delay for non-central molecules is greater by more than 2 years compared to the median delay of central molecules which is on the order of one year. The faster diffusion of centrally approved

\footnotetext{
${ }^{23}$ Kaplan-Meier estimate for Spain not available, the restricted mean which provides a lower bound for the median is reported
} 
molecules can be attributed to the elimination of differentials in regulatory approval times as well as a potentially higher therapeutic/commercial value of the centrally approved drugs.

Central approval speeds up the introduction of molecules in laggard countries such as France, Italy and Spain. Spain exhibits the most dramatic reduction in median delays -a reduction from 5 years to 1.5 years- among the five main European pharmaceutical markets due to central approval. For France and Italy the reduction is on the order of half a year only. The centralized EU procedure is compulsory for all medicinal products derived from biotechnology and other high technology processes. If the product does not belong to the designated disease categories ${ }^{24}$ for central approval, companies can submit an application for a centralized marketing authorization, provided the product offers a significant therapeutic, scientific or technical innovation $^{25}$. A more homogenous cross-country launch for central molecules across the EU indicates that on average European patients have more equitable access to drugs that have priority from a health policy perspective-at least to the extent that these drugs are diffused at comparable times (the take-up and access post-launch may introduce further differentials in access due to differences in reimbursement policies as well as cultural factors).

\subsection{Trends in the Adoption of Generic Products}

The lags in generic entry across countries depend on differentials in patent expiry dates or market exclusivity as well as originator firm strategies to block or delay generic competition. Due to unavailability of data to control for patent expiry dates or originator firm actions, the estimates provide generic lags as the time elapse between the first global generic product launch and local generic launch for a given molecule-country pair. This measure therefore provides only a relative measure of differentials in the timing of generic availability across countries.

\section{Evolution of Median Delays over Decades}

The trend in overall median delays for generic molecules that launched both in the US\&UK from 1960 to 2008 is similar to the case in the cross-country diffusion of pharmaceutical innovation; the diffusion of imitative pharmaceutical has accelerated over time (see Figure 7). In each period, medians are reduced by half compared to the previous period. The overall median delay has decreased from 26 to 14.5 years from 1960-1984 to 1984-1995 and to 8 years during 19952008.

\footnotetext{
${ }^{24}$ These categories include all human medicines intended for the treatment of HIV/AIDS, cancer, diabetes, neurodegenerative diseases, auto-immune and other immune dysfunctions, and viral diseases, and all designated orphan medicines intended for the treatment of rare diseases

${ }^{25} \mathrm{http}: / / \mathrm{www} . e m e a . e u r o p a . e u / /$
} 
Figure 7. Overall median delays of generics with respect to period of global launch

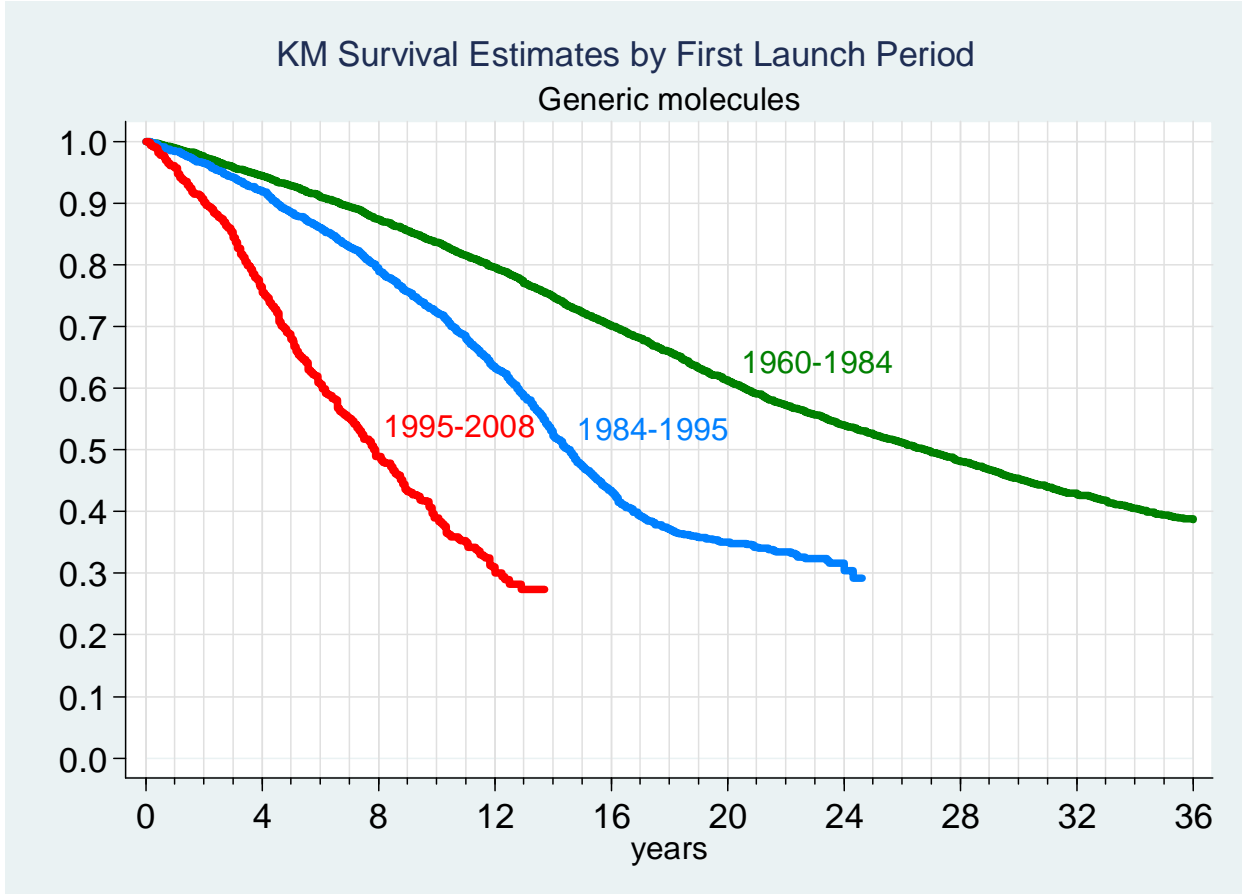

In parallel to the case with innovative molecules, fixed and random effect Cox estimates for the impact of the period of first launch indicate that generics launched significantly faster after 1984 . The Hausman test comparing fixed and random effects indicates that the shared frailty specification is correct (p-value 0.154). First launch during 1984-1995 is associated with a 2.5 times faster hazard rate compared to first launch during 1960-1984, and first launch during 19952008 is associated with a 6.5 times faster hazard rate compared to first launch during 1960-1984. The significance of the difference in the median delays across decades can also be inferred from the non-intersecting confidence intervals of medians estimated by Stata 10 (see Table A.2). The acceleration in generic adoption over time can be mainly attributed to new regulations in the US and EU that have enabled generic drug development before patent expiry and reduced capital requirements by obviating the need to reproduce data from clinical trials.

\subsubsection{0-1984: Stringency in MA Regulations and the US drug lag}

In the previous sections, significant lags in the US were observed for innovative products (i.e. new molecules launching for the first time). As Figure 8 shows the US exhibits no lag with respect to the adoption of pharmaceutical imitation. Based on a cross-country perspective, Italy, Spain and France adopt generics latest, and are surpassed by Germany and the UK. This pattern in Europe is broadly in line with the case for innovative pharmaceutical diffusion; except for the 
fact that UK lags behind Germany during this period by about 3 years (see Table A.3 for the exact figures). Also, generics reach Japan relatively fast during this period compared to the relative adoption speed of innovative molecules in Japan.

Figure 8. Survival Estimates for Generics: 1960-1984

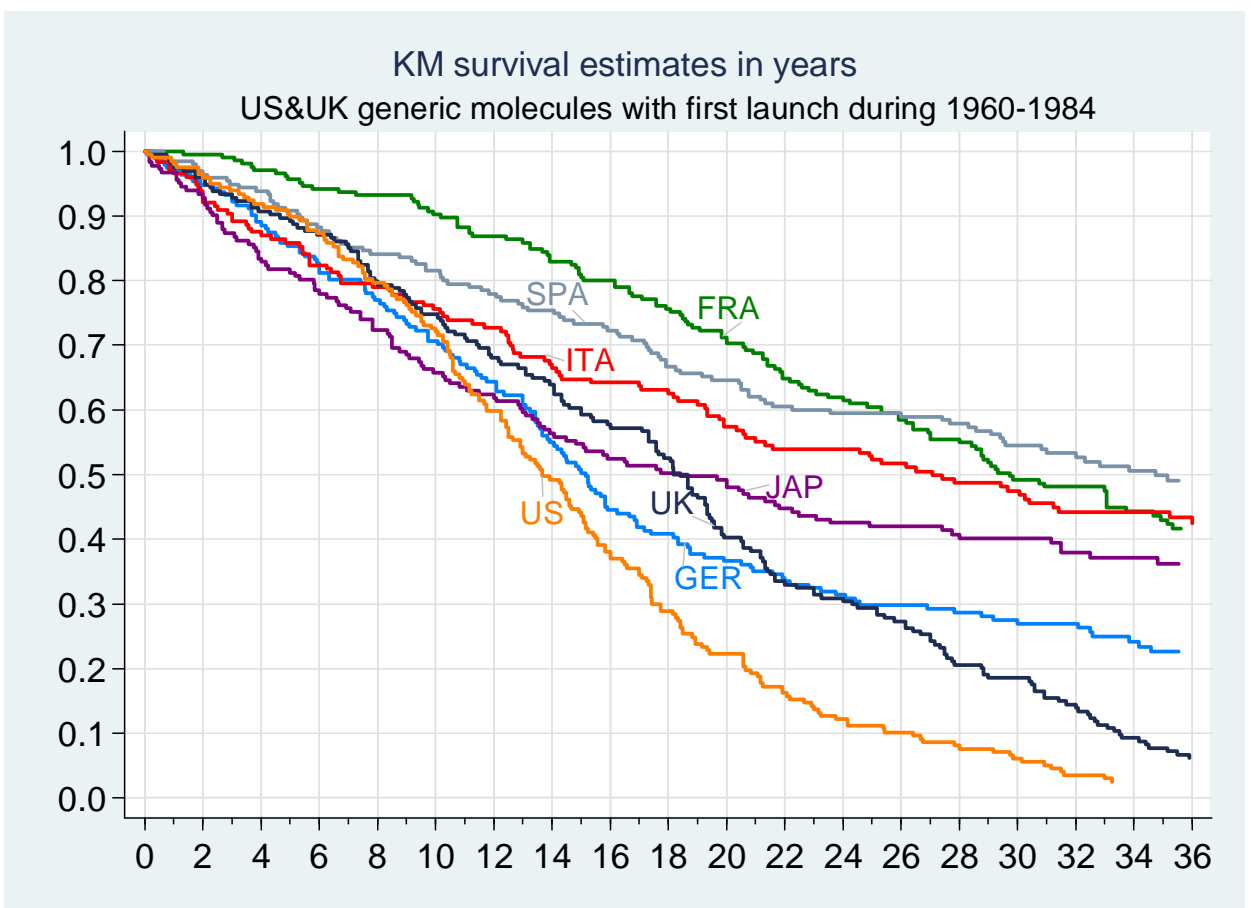

\subsubsection{4-1995: The Hatch-Waxman Act and Improved Generic Access in the US}

The Hatch-Waxman Act of 1984 aimed to facilitate generic entry by eliminating the entry barrier of duplicative testing required for generic substitutes while ensuring adequate return for innovator firms through patent restoration (Wittner 2004). As the most immediate benefit, the 1984 Act allowed generic manufacturers develop generic drugs before patent expiry of the originator product (often referred as the "Bolar" clause) ${ }^{26}$. Generic producers were allowed to reference the originator's safety and efficacy data obviating the need to repeat the same tests, which reduced development costs substantially and therefore alleviated barriers to generic entry. The Act introduced 180 days of market exclusivity period to the first company to file a new generic application (known as ANDA, Abridged New Drug Application).

\footnotetext{
${ }^{26}$ The name is derived from a landmark case between Roche and the generic companies Bolar. Bolar won the right to start developing the generic copy of Roche's patented compound Flurazepam Hydrochloride prior to its patent expiry, which was incorporated into the 1984 Act.
} 
Figure 9. Survival Estimates for Generics: 1984-1995

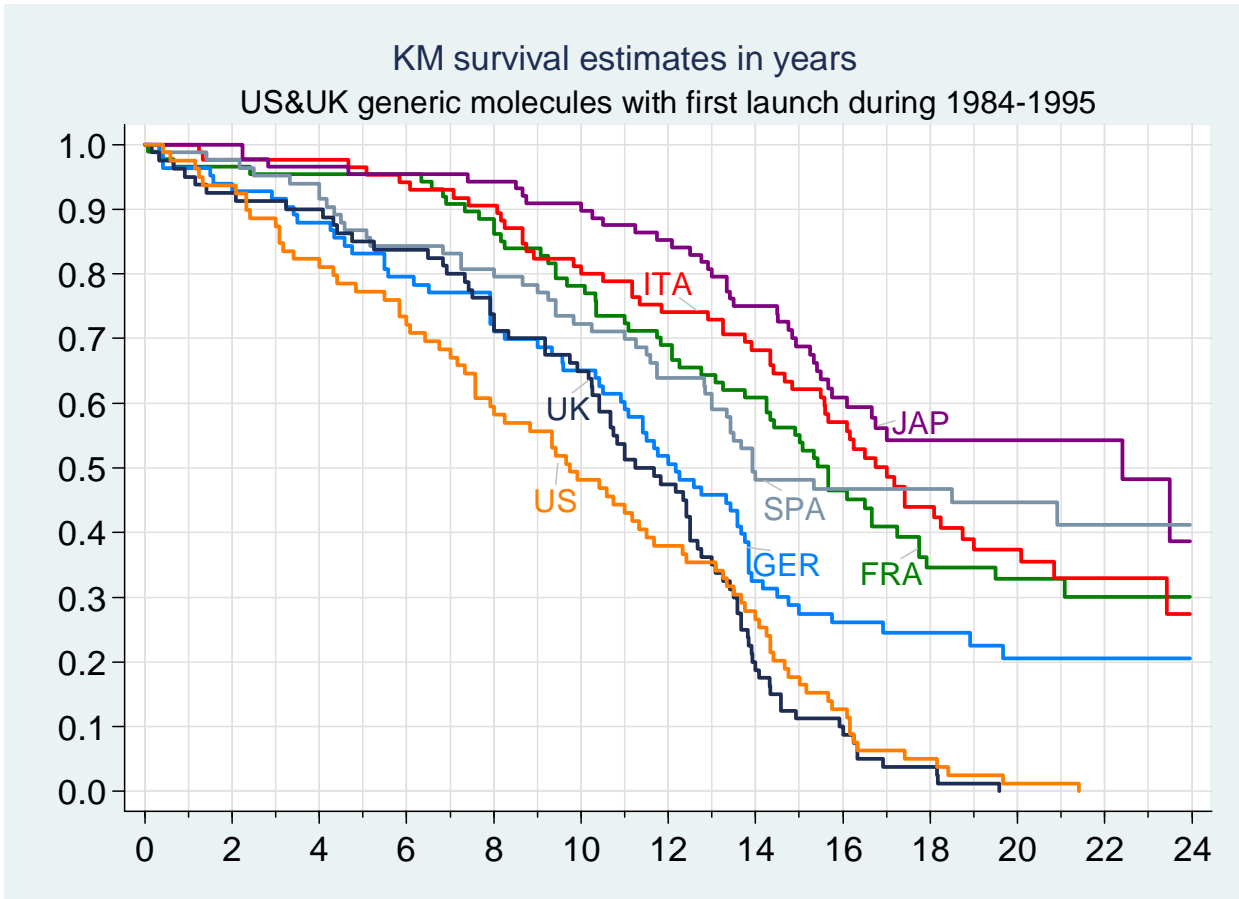

Figure 9 shows that the pattern of differential lags during 1984-1995. Compared to the 19601984 three main differences emerge. First, following the provisions for quicker generic entry in the Hatch-Waxman Act, the median delay in the US is reduced by 4 years (from 14 years to about 10 years). Second, the Japanese lag for generics increases by 4 years. Third, UK and Germany show equally fast generic adoption with a median lag on the order of 11-12 years. Finally, France, Italy and Spain follow with a median delay of 14-17 years.

\subsubsection{5-2008: EMA and New Generic Legislations in Europe}

The period from 1995 to 2008 witnessed important regulatory changes in generic legislations both in the US and Europe. Europe followed the US in providing incentives for generic development and timely market access in Europe. The US, on the other hand, focused mainly on the prevention of originator firm strategies to delay or block generic competition.

\section{Changes in the US Generic Legislation}

Two revisions (McCain-Schumer legislation in 2002, Gregg-Schumer Act in 2003) to HatchWaxman Act in the US sought to improve the balance between the needs of the branded companies and those of the generic companies. First, the new revisions set up a new mechanism to prevent the inclusion of frivolous patents or those filed at the last moment as a blocking mechanism. Second, the new legislation addressed the use of 180-day exclusivity period by 
generic companies for special arrangements with originators as a means to prevent market entry of other generics ${ }^{27}$. Gregg-Schumer revisions included "forfeiture" provisions which put the generics company under risk of losing the exclusivity if found to have made such an arrangement.

\section{Changes in the European Generic Legislation}

Europe's fragmented market structure has presented a major barrier to generic growth compared to the US market where federal law applies uniformly across different states. Directive 2004/27/EC has aimed to remove some of these barriers by updating Directive 2001/83. As with the US Hatch-Waxman Act, the legislation was intended to balance the needs of the branded pharmaceutical companies and generics companies. Directive 2001/83, the overall body of EU law governing the manufacture and trade in pharmaceuticals, had flows such as the lack of a generic-product definition and allowed branded companies to withdraw reference products before generic entry.

The new laws introduced a specific "generic" definition. One of the most important aspects for generics companies was the "Bolar" clause permitting generic companies to do their own development work within the EU during the period of patent protection for the original molecule. The practical impact of the clause on the timing of product launches may be minimal because wherever the development is carried out, generics cannot be launched prior to patent expiry. The main benefit however is that companies could maintain generic drug development in the $\mathrm{EU}^{28}$.

Under the new legislation, the same product can be used as a reference product for generics everywhere in the EU even if not registered in particular countries. This is a small step towards unification of European generic legislation. An additional benefit of the new legislation is that if originator companies withdraw a brand before any generic versions are marketed, the generics can still use it as a reference product. Finally, the establishment of the EMA in 1995 had little direct impact on generics companies. However, the centralized procedure is open to generics provided that the original is approved through the centralized system (Wittner 2004) .

\section{Generic Lags across Markets follow the Pattern of Non-Generic Lags}

Figure 10 demonstrates that the pattern of launch for the first imitative generic product is quite

\footnotetext{
${ }^{27}$ According to the 1984 Act, if the first generic company chose not to market the generic copy, all other generic competitors from the market would be excluded and all competition would be blocked for a period of 180 days. Authorized generics, copies made under license from the innovator companies, were introduced whereby the originator receives royalties on sales in return. For example, Par Pharma's generic version of Glaxo's Paxil (Paroxetine) was launched with Glaxo's approval even though Apotex had obtained six-month exclusivity for its own generic.

${ }^{28}$ As mentioned before, the SPC had prevented generic companies from engaging in R\&D prior to patent expiry.
} 
similar to the pattern for innovative molecules (Figure 4) ${ }^{29}$. New generic legislations have proven effective in the EU in further reducing the generic lag. The fastest adopters are as usual markets with relatively high originator prices (the US, UK and Germany) that offer higher profit prospects for imitative products. The median delay for the leaders is on the order of 4-5 years, with a reduction of 5-6 years compared to 1984-1995. More regulated markets (Italy, Spain and France) lag by about 5 years behind the leaders, with a median delay of 9-10 years (which is a significant reduction from 14-17 years in 1984-1995).

Figure 10. Survival Estimates for Generics: 1995-2008

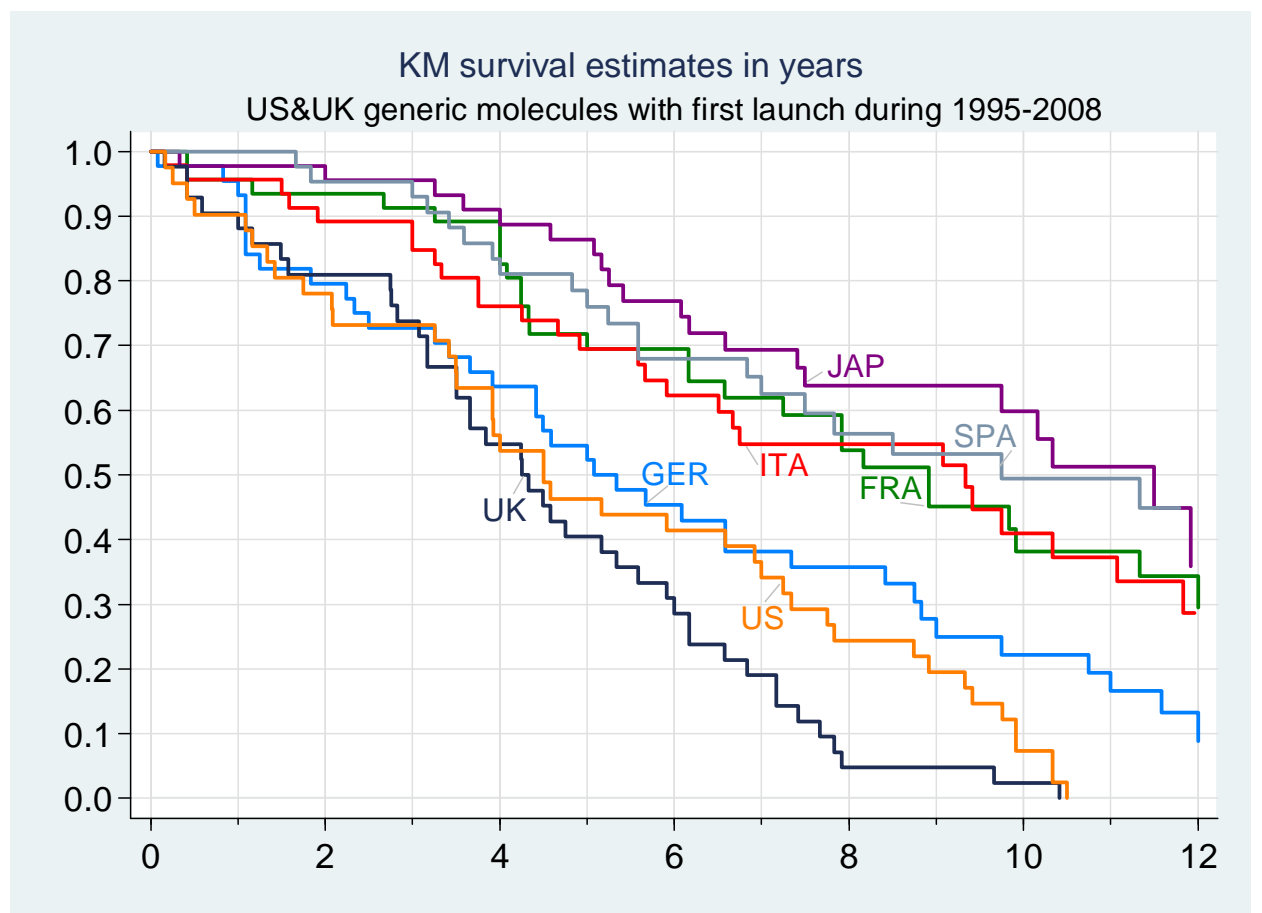

Japanese lag for the adoption of imitative products is not as dramatic as for innovative molecules; however, Japan is still the slowest market among the biggest seven markets with a median delay of 11 years. Generic drugs have been regarded in Japan as inferior. Similarly, physicians have had financial incentives for prescribing non-generic drugs. However, recently the government has initiated educational and advertising campaigns to improve generic use as well as changes on the provider side including elimination of the link between prescribing practices and physician salaries (Business Insights 2009).

\footnotetext{
${ }^{29}$ Similar to the non-generic case, equality by country, atc1, form 1 and first launch period rejected (p-value $<0.001$ for all).
} 
Similar survival profiles for new molecules and generic products indicate that the negative impact of price controls on the launch timing of pharmaceutical innovation translates to the adoption of imitative pharmaceutical products. The launch patterns show that regulated markets access innovation later but also face temporal disadvantage in terms of their access to costsaving generic products. To what extent this is balanced by lower branded prices remains an open question for further exploration.

\section{CONCLUSIONS}

This paper has sought to provide an overview of the evolution of the drug lag for pharmaceutical innovation (new molecules) as well as generic copies across the main OECD markets with regards to changes in the regulatory environment during 1960-2008 using non parametric methods. This is the first study to provide a descriptive evolution of relative lags across a number of markets over a lengthy period of time and a comprehensive set of molecules, both for innovative products and generic copies.

Lower transaction costs due to reductions in geographical barriers and lower regulatory costs (harmonized market authorization procedures, strengthened IP rights, patent term restorations) have exerted a downward pressure over time on median delays in individual countries as well as overall delays across the main OECD markets. All markets experience a decreasing trend over time for median delays following global launch. With the wider use of the centralized procedure over the coming years, the delays in the diffusion of pharmaceutical innovation across the EU may be further smoothed out. However, the relative lags across countries remain significant both for new molecules and generic products due to the variety in pricing and reimbursement regulations. In fact, an important finding is that the negative impact of price controls on new molecules translates to a later generic availability which suggests that regulation delays patient access to new pharmaceutical technologies but also creates opportunity costs for governments through foregone savings due to later generic availability compared to free markets. Assessing the impact on overall welfare, however, would require a comparison of savings from lower branded product prices and savings foregone due to late generic launch and possibly lower generic penetration. Relative delays in the diffusion of generics are expected to decrease further due to the impact of the new European legislation in 2004 and the push for genericization as a cost-containment mechanism in regulated markets that have been further challenged by the recent economic downturn.

Globally, the relative lags exhibit a change in the geographical pattern of lags over time. The US lag back in 1960s has switched to more price stringent European markets throughout 1960-2008. 
Relatively free-priced European markets of Germany and the $\mathrm{UK}^{30}$, which also have strong local pharmaceutical industries, lead in the EU as the fastest adopters of pharmaceutical innovation (and imitation). Product launch strategically takes place first in higher-priced EU markets as a result of threat of arbitrage and price dependency across the member states, which puts European markets with low prices and/or small market sizes such as Spain and Portugal at a disadvantage. Paradoxically, the Japanese market with its large market size and relatively high prices remains a laggard throughout 1960-2008. The idiosyncratic nature of clinical trial requirements in Japan has been the major driver of asymmetric costs for foreign pharmaceutical firms. Harmonization efforts on foreign clinical data use seem to be taking effect slowly and expected future rise in the use of the bridging strategy may further reduce the Japanese drug lag in the upcoming years.

The R\&D activity of leading pharmaceutical companies is largely carried out in the major OECD markets. Reducing delays in these markets will offer higher returns to R\&D and stimulate further innovation contributing to dynamic efficiency over the long run. On the other hand, new pharmaceutical technologies impose additional pressure on the tight health care budgets and quick diffusion of new technologies with uncertain benefits could lead to inefficiencies in the provision of health care (Garber and Skinner 2008). The introduction of new drugs in individual markets, therefore, should be balanced out with the expansion of drug expenditure and the evidence of cost-effectiveness. From a cross-country perspective, reducing the differential delays for globally important molecules will enable a more equitable access to new and possibly more effective treatment alternatives.

Finally, the non-parametric approach adopted in this paper offered an exploratory analysis into the nature of the drug delay across countries and over time. The methodological approach can be extended in future research to analyze the impact of policy changes in 1984 and 1995 by a difference-in-differences (DiD) analysis that treats policy changes as quasi-experiments. In addition, the impact of regulation on the international adoption speed of new molecules and generic competition can be further assessed in a (semi-) parametric survival analysis by treatment dummies for regulation or proxying the net effect of regulation with expected prices.

\footnotetext{
${ }^{30}$ However, prices may be indirectly affected through regulations in other parts of the market. In the UK profits are regulated through the PPRS (Pharmaceutical Price Regulation Scheme) and products are subject to NICE appraisals for Cost-Effectiveness ("the fourth hurdle"). The Flexible Pricing scheme and Risk Sharing Agreements introduced in the 2009 PPRS will further emphasize value-for-money in NHS purchases of medicinal products. In Germany reimbursement regulation through reference pricing includes patented pharmaceuticals in reference groups unless novelty and therapeutic improvement is demonstrated and companies take this into consideration when setting prices.
} 


\section{Acknowledgements}

We are grateful for the financial support provided by Merck Foundation Trust, and to Tim

Williams and Elizabeth Finch from MSD, UK for their help during the data collection process. 


\section{Appendix}

Table A.1 Mean and Median Launch Lags over Time for US \& UK Molecules (Non-Generic)

\begin{tabular}{|c|c|c|c|c|c|c|c|c|c|c|c|c|}
\hline & \multicolumn{4}{|c|}{$1995-2008$} & \multicolumn{4}{|c|}{$1984-1995$} & \multicolumn{4}{|c|}{$1960-1984$} \\
\hline Country & Mean & $\begin{array}{c}\text { Std Error - } \\
\text { Mean }\end{array}$ & Median & $\begin{array}{l}\text { Std Error } \\
\text { - Median }\end{array}$ & Mean & $\begin{array}{c}\text { Std Error - } \\
\text { Mean }\end{array}$ & Median & $\begin{array}{c}\text { Std Error - } \\
\text { Median }\end{array}$ & Mean & $\begin{array}{c}\text { Std Error - } \\
\text { Mean }\end{array}$ & Median & $\begin{array}{c}\text { Std Error - } \\
\text { Median }\end{array}$ \\
\hline Australia & $3.598\left(^{*}\right)$ & 0.264 & 1.752 & 0.029 & $8.146(*)$ & 0.58 & 4.838 & 0.118 & *) & 0.873 & 12.252 & 0.256 \\
\hline Austria & $2.181(*)$ & 0.212 & 0.999 & 0.015 & $6.514(*)$ & 0.559 & 3.42 & 0.077 & $19.254(*)$ & 1.02 & 9.415 & 0.279 \\
\hline Belgium & $5.720\left(^{*}\right)$ & 0.359 & 2.667 & 0.058 & $9.137(*)$ & 0.697 & 3.666 & 0.133 & $19.791\left(^{*}\right)$ & 1.065 & 8.501 & 0.446 \\
\hline Canada & $3.431\left(^{*}\right)$ & 0.281 & 1.336 & 0.032 & $7.402(*)$ & 0.592 & 4 & 0.084 & $13.257(*)$ & 0.81 & 6.084 & 0.124 \\
\hline Finland & $2.259(*)$ & 0.208 & 0.999 & 0.014 & $7.397(*)$ & 0.603 & 3.337 & 0.09 & $22.804(*)$ & 1.07 & 13.999 & 0.573 \\
\hline France & $2.903(*)$ & 0.233 & 1.585 & 0.022 & $6.482(*)$ & 0.524 & 3.329 & 0.092 & $16.558(*)$ & 0.942 & 6.585 & 0.224 \\
\hline Germany & 1.444 & 0.157 & 0.668 & 0.008 & $4.703(*)$ & 0.473 & 2.001 & 0.042 & $11.576(*)$ & 0.86 & 3.001 & 0.070 \\
\hline Greece & $.138(*)$ & 0.279 & 2.166 & 0.039 & $7.798(*)$ & 0.565 & 4.58 & 0.095 & $22.250(*)$ & 0.998 & 14.412 & 0.440 \\
\hline Italy & 2.927 & 0.212 & 1.749 & 0.015 & $6.227(*)$ & 0.521 & 3.584 & 0.058 & $16.019\left(^{*}\right)$ & 0.964 & 6.253 & 0.133 \\
\hline Japan & $7.885(*)$ & 0.338 & 6.582 & 0.194 & $12.441(*)$ & 0.71 & 9.673 & 0.231 & $21.218(*)$ & 1.034 & 11.414 & 0.304 \\
\hline Netherlands & $3.042(*)$ & 0.319 & 0.75 & 0.02 & $5.726(*)$ & 0.611 & 1.837 & 0.057 & $19.158(*)$ & 1.105 & 7.247 & 0.317 \\
\hline Poland & $4.402(*)$ & 0.264 & 3.001 & 0.049 & $9.395\left(^{*}\right)$ & 0.495 & 7.335 & 0.074 & $27.980(*)$ & 0.666 & 26.497 & 0.204 \\
\hline Portugal & $8.521\left(^{*}\right)$ & 0.372 & 13.254 & & $12.884(*)$ & 0.711 & 8.83 & 0.272 & $25.436(*)$ & 1.1 & 19.162 & 0.748 \\
\hline S.Africa & $5.590(*)$ & 0.344 & 3.168 & 0.063 & $7.877(*)$ & 0.611 & 4 & 0.122 & $21.776(*)$ & 0.985 & 20.246 & 0.415 \\
\hline Spain & $6.318(*)$ & 0.375 & 2.667 & 0.061 & $10.117(*)$ & 0.667 & 5.84 & 0.142 & $19.309\left(^{*}\right)$ & 1.06 & 7.077 & 0.221 \\
\hline Sweden & $2.809(*)$ & 0.286 & 0.747 & 0.016 & $8.311(*)$ & 0.668 & 4.167 & 0.155 & $27.842(*)$ & 1.086 & 27.83 & \\
\hline Switzerland & $2.964\left(^{*}\right)$ & 0.261 & 1.413 & 0.027 & $5.842(*)$ & 0.537 & 2.828 & 0.071 & $12.799\left(^{*}\right)$ & 0.931 & 4.085 & 0.143 \\
\hline Turkey & $5.701(*)$ & 0.299 & 4 & 0.041 & $9.381(*)$ & 0.552 & 6.834 & 0.095 & $25.803(*)$ & 0.903 & 21.832 & 0.299 \\
\hline UK & 1.27 & 0.115 & 0.75 & 0.009 & 3.151 & 0.271 & 1.914 & 0.062 & 8.817 & 0.584 & 3.083 & 0.097 \\
\hline
\end{tabular}




\begin{tabular}{|l|c|c|c|c|c|c|c|c|c|c|c|c|} 
US & 0.665 & 0.102 & 0.001 &. & 3.602 & 0.277 & 2.664 & 0.055 & 10.052 & 0.469 & 7.666 & 0.120 \\
\hline OVERALL & $3.829\left(^{*}\right)$ & 0.067 & 1.667 & 0.038 & $7.636\left(^{*}\right)$ & 0.135 & 4.085 & 0.113 & $18.823\left(^{*}\right)$ & 0.219 & 10.587 & 0.326 \\
\hline
\end{tabular}

(* largest observed analysis time is censored, mean is underestimated)

Table A.2 Median delays and confidence intervals by period of first launch (generic molecules)

\begin{tabular}{|c|c|c|c|c|c|}
\cline { 2 - 6 } \multicolumn{1}{c|}{} & Subjects & median & Std. Err. & \multicolumn{2}{c|}{$[95 \%$ Conf. Interval] } \\
\hline $1960-1984$ & 3924 & 26.83 & 0.54 & 25.75 & 27.83 \\
\hline $1984-1995$ & 1688 & 14.58 & 0.23 & 14.00 & 14.92 \\
\hline $1995-2008$ & 869 & 7.83 & 0.31 & 7.33 & 8.58 \\
\hline
\end{tabular}


Table A.3 Mean and median launch delays for generic molecules that launched in US and UK

\begin{tabular}{|c|c|c|c|c|c|c|c|c|c|c|c|c|}
\hline \multirow[b]{2}{*}{ Country } & \multicolumn{4}{|c|}{$1995-2008$} & \multicolumn{4}{|c|}{ 1984-1995 } & \multicolumn{4}{|c|}{ 1960-1984 } \\
\hline & Mean & \begin{tabular}{|c} 
Std \\
Error - \\
Mean \\
\end{tabular} & Median & $\begin{array}{c}\text { Std Error } \\
\text { Median }\end{array}$ & Mean & $\begin{array}{c}\text { Std } \\
\text { Error - } \\
\text { Mean } \\
\end{array}$ & Median & $\begin{array}{c}\text { Std Error - } \\
\text { Median }\end{array}$ & Mean & $\begin{array}{c}\text { Std } \\
\text { Error - } \\
\text { Mean } \\
\end{array}$ & Median & $\begin{array}{r}\text { Std Error } \\
\text { Median }\end{array}$ \\
\hline AUSTRALIA & $7.425(*)$ & 0.712 & 8.085 & 8.085 & $15.446\left(^{*}\right)$ & 0.831 & 16 & 0.073 & $27.460(*)$ & 1.05 & 24.586 & 0.355 \\
\hline AUSTRIA & $7.877(*)$ & 0.711 & 7.915 & 7.915 & $16.248(*)$ & 0.808 & 14.001 & 0.146 & $31.961\left(^{*}\right)$ & 1.189 & 33.418 & 0.871 \\
\hline BELGIUM & $10.052(*)$ & 0.674 & . & . & $18.075\left(^{*}\right)$ & 0.721 & 17.084 & . & $33.843\left(^{*}\right)$ & 1.069 & 39.086 & 0.871 \\
\hline CANADA & $6.560(*)$ & 0.632 & 6.916 & 6.916 & $12.981\left(^{*}\right)$ & 0.895 & 10.242 & 0.306 & $22.390\left(^{*}\right)$ & 1.063 & 17.333 & 0.226 \\
\hline FINLAND & $8.098(*)$ & 0.72 & 7.417 & 7.417 & $16.553\left(^{*}\right)$ & 0.796 & 16 & 0.353 & $31.367\left(^{*}\right)$ & 1.279 & 31.496 & \\
\hline FRANCE & $8.610(*)$ & 0.661 & 8.914 & 8.914 & $15.912\left(^{*}\right)$ & 0.754 & 15.663 & 0.17 & $31.178(*)$ & 1.092 & 29.752 & 0.463 \\
\hline GERMANY & $6.060(*)$ & 0.6 & 5.081 & 5.081 & $12.768\left(^{*}\right)$ & 0.793 & 12.167 & 0.207 & $20.877\left(^{*}\right)$ & 1.18 & 15.168 & 0.136 \\
\hline GREECE & $9.261(*)$ & 0.676 & 8.413 & 8.413 & $15.215\left(^{*}\right)$ & 0.93 & 15.253 & 0.38 & $30.055\left(^{*}\right)$ & 1.244 & 32.838 & 0.567 \\
\hline ITALY & $8.374(*)$ & 0.69 & 9.339 & 9.339 & $16.817\left(^{*}\right)$ & 0.728 & 16.999 & 0.138 & $28.294\left(^{*}\right)$ & 1.422 & 27.083 & 0.801 \\
\hline JAPAN & $9.782(*)$ & 0.646 & 11.496 & 11.496 & $18.784\left(^{*}\right)$ & 0.719 & 22.412 & 0.497 & $24.920\left(^{*}\right)$ & 1.443 & 18.412 & 0.532 \\
\hline NETHERLA & $7.451(*)$ & 0.736 & 6.418 & 6.418 & $15.386(*)$ & 0.965 & 13.413 & 0.265 & $32.053(*)$ & 1.123 & 32.832 & 0.602 \\
\hline POLAND & $7.858(*)$ & 0.703 & 7.168 & 7.168 & $13.114(*)$ & 0.815 & 11.086 & 0.192 & $30.611\left(^{*}\right)$ & 0.901 & 29.495 & 0.278 \\
\hline PORTUGAL & $9.259(*)$ & 0.645 & 11.496 & 11.496 & $15.922(*)$ & 0.919 & 16 & 0.303 & $35.085\left(^{*}\right)$ & 1.151 & & \\
\hline SAFRICA & $8.911(*)$ & 0.606 & 8.832 & 8.832 & $16.261\left(^{*}\right)$ & 0.779 & 14.834 & 0.204 & $32.282(*)$ & 1.228 & 31.247 & 0.385 \\
\hline SPAIN & $8.965(*)$ & 0.633 & 9.747 & 9.747 & $16.110(*)$ & 0.903 & 13.919 & 0.572 & $31.147(*)$ & 1.294 & 34.749 & 0.846 \\
\hline SWEDEN & $8.119(*)$ & 0.746 & 8.167 & 8.167 & $16.578\left(^{*}\right)$ & 0.823 & 15.001 & 0.267 & $36.388(*)$ & 1.103 & & \\
\hline SWITZERLAND & $10.530(*)$ & 0.672 & & & $17.173(*)$ & 0.758 & 15.918 & 0.247 & $30.654\left(^{*}\right)$ & 1.222 & 29.248 & 0.893 \\
\hline TURKEY & $8.767(*)$ & 0.808 & 9.832 & 9.832 & $15.293(*)$ & 1.035 & 16.085 & 0.902 & $29.481\left(^{*}\right)$ & 1.198 & 28.413 & 0.529 \\
\hline UK & 4.486 & 0.388 & 4.252 & 4.252 & 10.596 & 0.507 & 11.25 & 0.182 & 18.619 & 0.772 & 18.168 & 0.147 \\
\hline US & 5.224 & 0.516 & 4.504 & 4.504 & 9.754 & 0.585 & 9.752 & 0.182 & 14.767 & 0.589 & 13.67 & 0.129 \\
\hline Total & $8.117(*)$ & 0.16 & 7.833 & 7.833 & $15.314\left(^{*}\right)$ & 0.191 & 14.579 & 0.23 & $28.615\left(^{*}\right)$ & 0.27 & 26.831 & 0.544 \\
\hline
\end{tabular}

(* largest observed analysis time is censored, mean is underestimated) 


\section{References}

Annon, A. (1994). 'A Drug Tsar is Born', The Economist.

Barral, P. E. (1985). Ten Years of Results in Pharmaceutical Research Throughout the World.(1975-1984), Prospective et Sante Publique.

Berlin, H. and B. Jonsson (1986). 'International dissemination of new drugs: a comparative study of six countries', Managerial and Decision Economics 7(4), pp. 235-242.

Branes, J. M. (2007). Patent technology: transfer and industrial competition Nova Science Publishers.

Busfield, J. (2003). 'Globalization and the pharmaceutical industry revisited', International Journal of Health Services 33(3), pp. 581-605.

Business Insights (2009). 'The Japanese Pharmaceutical Market Outlook to 2014: Policy environment, market structure, competitive landscape, growth opportunities'.

Coppinger, P. L., C. C. Peck, et al. (1989). 'Understanding comparisons of drug introductions between the United States and the United Kingdom. Reply', Clinical pharmacology and therapeutics 46(2), pp. 139-145.

Danzon, P. M. and A. Epstein (2005). 'Launch and Pricing Strategies of Pharmaceuticals in Interdependent Markets', iHEA Conference.

Danzon, P. M. and A. J. Epstein (2008). 'Launch and Pricing Strategies of Pharmaceuticals in Interdependent Markets', NBER Working Paper No. W14041.

Danzon, P. M. and J. D. Ketcham (2004). Reference Pricing of Pharmaceuticals for Medicare: Evidence from Germany, the Netherlands, and New Zealand. Cutler DM, Garber AM, eds. Frontiers in Health Policy Research (National Bureau of Economic Research, Volume 7).

Cambridge, Mass: The MIT Press: 1-54.

Danzon, P. M., Y. Wang, et al. (2005). 'The Impact of Price Regulation on the Launch Delay of New Drugs - Evidence from Twenty-Five Major Markets in the 1990s', Health Economics 14, pp. 269-292.

DG Competition (2009). 'Pharmaceutical Sector Inquiry Final Report', Available at http:/ec.europa.eu/competition/sectors/pharmaceuticals/inquiry/staff working paper part1.pdf

Garber, A. M. and J. Skinner (2008). 'Is American Health Care Uniquely Inefficient?' The journal of economic perspectives: a journal of the American Economic Association 22(4), pp. 27.

Grabowski, H. G. (1980). 'Regulation and the International Diffusion of Pharmaceuticals', The International Supply of Medicines, pp. 5-36.

Hassett, K. A. (2004). 'Price Controls and the Evolution of Pharmaceutical Markets', American Enterprise Institute. 
Kaitin, K. I., N. Mattison, et al. (1989). 'The drug lag: an update of new drug introductions in the United States and in the United Kingdom, 1977 through 1987', Clinical pharmacology and therapeutics 46(2), pp. 121.

Kessler, D. P. (2004). 'The Effects of Pharmaceutical Price Controls on the Cost and Quality of Medical Care: A Review of the Empirical Literature', pp.

Kyle, M. (2007). 'Pharmaceutical Price Controls and Entry Strategies', The Review of Economics and Statistics 89(1), pp. 88-99.

Kyle, M. K. (2007). 'Strategic responses to parallel trade', National Bureau of Economic Research

Lichtenberg, F. (2003). 'Impact of Drug Launches on Longevity: Evidence from Longitudinal Disease Level Data from 52 countries, 1982-2001', pp.

Lichtenberg, F. R. (1996). 'Do (More and Better) Drugs Keep People Out of Hospitals?' American Economic Review 86, pp. 384-388.

Lichtenberg, F. R. (2005). 'The Impact of New Drug Launches on Longevity: Evidence from Longitudinal, Disease-Level Data from 52 Countries, 1982-2001', International Journal of Health Care Finance and Economics 5(1), pp. 47-73.

Parker, J. E. S. (1984). The International Diffusion of Pharmaceuticals, Macmillan Press Ltd.

Permanand, G. (2006). EU pharmaceutical regulation : the politics of policy-making.

Pharmaceutical Manufacturers Association (1993). PMA Annual Survey Report: Trends in US Pharmaceutical Sales and R\&D. Washington, DC.

Schoffski, O. (2002). 'Diffusion of Medicines in Europe', pp.

Tabata, Y. and C. Albani (2008). 'Globalising clinical development in Japan', Journal of Commercial Biotechnology 14(1), pp. 73-78.

Thomas, L. G. (2001). The Japanese Pharmaceutical Industry: The new drug lag and the failure of industrial policy, Edward Elgar Publishing.

Uyama, Y., T. Shibata, et al. (2005). 'Successful bridging strategy based on ICH E5 guideline for drugs approved in Japan\&ast', Clinical Pharmacology \& Therapeutics 78(2), pp. 102-113.

Vernon, J. (2005). 'Examining the link between price regulation and pharmaceutical R\&D investment', Health Economics 14(1), pp. 1-17.

Vogler, S. (2008). Pharmaceutical Pricing and Reimbursement Information Report.

Wardell, W. M. (1973). 'Introduction of new therapeutic drugs in the United States and Great Britain: an international comparison', Clinical Pharmacology \& Therapeutics 14(5), pp. 773-90. 
Wardell, W. M. (1974). 'Therapeutic implications of the drug lag', Clinical Pharmacology \& Therapeutics 15(1), pp. 73-96.

Wardell, W. M. (1978). 'The drug lag revisited: comparison by therapeutic area of patterns of drugs marketed in the United States and Great Britain from 1972 through 1976', Clinical Pharmacology \& Therapeutics 24(5), pp. 499-524.

Wertheimer, A. I. and T. M. Santella (2004). 'Pharmacoevolution: the advantages of incremental innovation', IPN Working Papers on Intellectual Property, Innovation and Health.

Wittner, P. (2004). Growth Strategies in Generics: Innovative and aggressive strategies and their impact on branded pharmaceuticals. London.

WTO OMC. (2003). "TRIPS and pharmaceutical patents, Fact Sheet." 2008, Available at http://www.wto.org/english/tratop_e/trips_e/tripsfactsheet_pharma_e.pdf. 
For further information on this or any of the

Health publications contact:

Naho Ollason

Managing Editor

LSE Health

The London School of Economics and Political Science

Houghton Street

London WC2A 2AE

Tel: +44 (0)20 79553733

Fax: +44(0)20 79556090

Email: n.ollason@se.ac.uk

Website: www.lse.ac.uk/collections/LSEHealth/ 